\title{
GESTÃO FISCAL COMO DETERMINANTE DA TRANSPARÊNCIA FISCAL ATIVA: UM ESTUDO NOS MUNICÍPIOS PARAIBANOS ${ }^{1}$
}

\section{FISCAL MANAGEMENT AS A DETERMINANT OF THE ACTIVE TAX TRANSPARENCY: A STUDY IN THE CITIES OF PARAÍBA}

\author{
Leandro da Costa Santos \\ Mestre em Ciências Contábeis (UFPB) \\ Universidade Federal da Paraíba \\ leandrosantoscont@gmail.com \\ Márcia Reis Machado \\ Doutora em Ciências Contábeis (USP) \\ Universidade Federal da Paraíba \\ marciareism@hotmail.com
}

\section{RESUMO}

Objetivo: Identificar se existe relação entre transparência fiscal ativa e gestão fiscal e como ocorre esta relação.

Fundamento: A pesquisa alicerçou-se nas teorias da Agência, Escolha Pública e do Gerenciamento de Impressão, uma vez que em sinergia, estas teorias explicam que na busca por seus interesses pessoais, o gestor público tende a escolher ações que maximizem a sua reeleição ou que mantenham o seu partido político no poder, direcionando esforços para o gerenciamento das informações que serão disponibilizadas ao cidadão.

Método: Para estimar a relação entre as variáveis de gestão fiscal representadas pelo Índice Firjan de Gestão Fiscal (IFGF) e a transparência fiscal ativa representada pelo Índice de Transparência Fiscal Ativa (ITFA), utilizou-se a regressão pooled OLS com dados em painel, utilizando modelos com e sem defasagem para as variáveis independentes. A amostra compreendeu 157 municípios paraibanos.

Resultados: Evidencia-se relação positiva entre a Gestão Fiscal do Gasto com Pessoal e Liquidez e o Índice de Transparência Fiscal Ativa, corroborando com o que discorrem as teorias da Agência, Escolha Pública e Gerenciamento de Impressão. Assim, quanto melhor a Gestão Fiscal nestas dimensões, melhor é a transparência dada às informações, uma vez que a divulgação de resultados positivos gera uma imagem melhor do gestor público (agente) perante o cidadão/eleitor (principal), melhorando a sua chance de reeleição ou a continuidade de seu partido político no poder.

Contribuições: De maneira geral, as evidências apresentadas nesta pesquisa contribuem para a academia ao destacar que resultados positivos de gestão fiscal estão relacionados com maior

\footnotetext{
${ }^{1}$ Artigo recebido em: 28/04/2019. Revisado por pares em: 24/11/2020. Reformulado em: 19/12/2020. Recomendado para publicação: 01/12/2020 por Lidiane Nazaré da Silva Dias (Editora Adjunta). Publicado em: 11/02/2021. Organização responsável pelo periódico: UFPB
} 
nível de transparência fiscal ativa nos municípios paraibanos, o que evidencia que as leis e normas não garantem, sozinhas, o nível adequado de transparência.

Palavras-chave: Gestão Fiscal. Transparência Pública. IFGF.

\section{ABSTRACT}

Objective: Identify whether and how a relationship between Active Tax Transparency and Fiscal Management occurs.

Background: Thus, the research was based on theories of the Agency, Public Choice and Print Management, since in synergy, these theories explain that in the search for their personal interests, the public manager tends to choose actions that maximize their re-election or maintenance of their political party in power, directing efforts to manage the information that will be made available to the citizen.

Method: To estimate the relationship between the variables fiscal Management indicators represented by the Fiscal Management FIRJAN Index (IFGF) and Fiscal Transparency Enables represented by the Fiscal Transparency Index Active (ITFA), we used pooled OLS regression with panel data, using models with and without lags for the independent variables. The sample comprised 157 cities in Paraíba.

Results: The results show a positive relationship between the Personnel Management and Liquidity Tax Management and the Active Tax Transparency Index, corroborating with what the theories of the Agency, Public Choice and Print Management describe. Thus, the better the Fiscal Management in these dimensions, the better the transparency given the information, since the dissemination of positive results generates a better image of the public manager (agent) vis-a-vis the citizen / voter (main), improving their chances of re-election or keeping his political party in power.

Contributions: In general, the evidence presented in this research contributes to the academy by highlighting that positive fiscal management results are related to a higher level of active tax transparency in the municipalities of Paraíba, which shows that the laws and norms do not guarantee, alone, the adequate level of transparency.

Key words: Fiscal Management. Public Transparency. IFGF.

\section{INTRODUÇÃO}

A Constituição Federal de 1988 (CF88), estabeleceu o direito de acesso à informação ao cidadão no âmbito público, deixando claro a importância da transparência das informações governamentais como ferramenta de controle social e accountability, sendo esta uma ponte para a diminuição da assimetria informacional que existe entre o governo e a sociedade.

A partir da CF88 diversas leis foram criadas objetivando a regulamentação do tema transparência governamental, como a Lei Complementar 101 promulgada no ano 2000, chamada de Lei da Responsabilidade Fiscal (LRF), que estabeleceu os planos, orçamentos e leis de diretrizes orçamentárias; as prestações de contas e o respectivo parecer prévio; o Relatório Resumido da Execução Orçamentária e o Relatório de Gestão Fiscal como instrumentos de transparência da gestão fiscal. Além disso, a LRF determina que estes documentos fiscais deverão ter ampla divulgação, inclusive em meios eletrônicos, o que os torna ferramentas para que o cidadão possa acompanhar o planejamento das contas públicas e os resultados do governo.

Posteriormente, a Lei Complementar nº 131 foi criada em 2009 (Lei da Transparência), que regulou a Transparência Ativa ao discorrer sobre a obrigação de disponibilização de informações de caráter orçamentário e financeiro, em tempo real e disponíveis em meio eletrônico por parte do governo para a sociedade em geral. Seguindo a evolução dos dispositivos legais, a Lei n. ${ }^{\circ} 12.527$ foi estabelecida em 2011, conhecida como Lei de Acesso à Informação (LAI), a qual dentre outras coisas estabeleceu que o acesso à informação pública seja a regra e que o sigilo seja a exceção. Desta- 
ca-se que apesar de ter sido promulgada em 2009, foi apenas em 2013 que a LAI obteve vigência plena, uma vez que foi concedido um prazo de 4 anos para os municípios com até 50 mil habitantes ajustarem-se as exigências da Transparência Ativa.

Todavia, mesmo com tantas leis assegurando o nível adequado de transparência, conforme dados evidenciados pela FIRJAN (2017), no ano de 2016 cerca de 2.091 municípios brasileiros descumpriram o que determina a Lei 101/2000 -LRF ao não declararem suas contas até a data limite (Art. 48 e 51 da LRF), ao encerrarem o exercício com mais restos a pagar do que recursos em caixa (Art. 42 da LRF) e ao ultrapassarem o limite de 60\% da Receita Corrente Líquida para despesas com pessoal (art. 20 da LRF). O número que mais se destaca é o de municípios sem transparência, tendo em vista que cerca de 937 municípios não divulgaram suas contas no prazo legal no ano de 2016. Municípios em descumprimento com a LRF estão presentes em todas as regiões do Brasil, mas percebe-se uma ênfase nos do Nordeste, o qual detém cerca de 52,5\% dos municípios em descumprimento com algum limite legal imposto pela LRF (FIRJAN, 2017).

Este cenário corrobora com o evidenciado por Zuccolotto e Teixeira (2014) que discorreram que a transparência do governo em todos os seus níveis depende de outros fatores, sejam eles internos ou externos, uma vez que os dispositivos legais não garantem por si só o nível de transparência.

Sobre o tema, algumas pesquisas evidenciaram fatores que afetam o nível de transparência no âmbito público, como o de Alt, Lassen e Shanna (2006) que estudaram a influência da política e da política fiscal no nível de transparência; Wehner e De Renzio (2013) que analisaram o papel de duas fontes importantes na demanda para a transparência fiscal: os cidadãos e os legisladores; Ribeiro e Zuccolotto (2012) que analisaram os fatores que influem no nível de transparência eletrônica dos municípios brasileiros; Mota, Diniz e Santos (2017) que pesquisaram sobre a influência da execução orçamentária (receitas e gastos) na transparência fiscal ativa nos municípios paraibanos; De Renzio e Wehner (2017) que pesquisaram variáveis como desempenho fiscal, governança e resultados de desenvolvimento favoráveis e sua relação com transparência pública e; ElBerry e Goeminne, (2020) que analisaram empiricamente os impactos das dimensões da transparência fiscal nos desvios de previsão do orçamento em países em desenvolvimento.

Conforme se observa, todas estas pesquisas revelaram a existência de fatores determinantes da transparência pública, demonstrando a importância de se pesquisar sobre este assunto, tendo em vista sua relevância para a sociedade.

Ainda sobre o tema, destaca-se que algumas teorias convergem para um melhor entendimento da transparência no âmbito público, como a Teoria da Agência, que se encontra relacionada com a disponibilização das informações, uma vez que segundo esta teoria, maior transparência ocasiona a redução da assimetria informacional e, consequentemente, diminuição do conflito de agência, melhorando a informação disponibilizada no âmbito público.

Outra teoria que se relaciona com a transparência governamental é a Teoria da Escolha Pública, a qual de acordo com Barros (2014) complementa e consegue explicar de maneira mais profunda a relação entre o agente e o principal no âmbito público. Segundo esta teoria, o gestor público tende a tomar suas decisões baseadas nas chances de reeleição, perquirindo assim, ações que ocasionem uma maior satisfação no cidadão/eleitor, ou seja, que eleve a quantidade de votos nas eleições, podendo inclusive gerar o gerenciamento de impressão.

Sobre gerenciamento de impressão, Rosenfeld (1997) explica que é o processo no qual os indivíduos buscam gerenciar a imagem que os outros têm a seu respeito. Busuioc e Lodge (2016) comentam que os gestores públicos têm incentivos para passarem a impressão de serem competentes. Assim, estes agentes tendem a manipular sua imagem frente a sociedade com maximização de informações positivas e minimização de informações negativas que possam transparecer falhas ou ações indevidas. 
Estas teorias em linha, fornecem o direcionamento de que o gestor público ao buscar objetivos pessoais, tende a ocultar informações negativas a fim de passar uma boa imagem da sua gestão, visando se manter no poder ou manter seu partido político, o que contribui para um baixo nível de transparência.

Corroborando com o que discorrem as teorias apresentadas, Cruz (2015) destaca que orçamentos distorcidos acabam gerando decisões discricionárias dos gestores públicos, devido a resultados referentes à gestão fiscal serem negativos e, dentre estas decisões, destaca-se a possibilidade de não disponibilização de informações públicas e relevantes à sociedade. Na mesma linha, Nobre (2017) enfatiza que no intuito de ocultar falhas que venham a prejudicar a imagem do gestor público, as informações orçamentárias e fiscais disponibilizadas tendem a se tornarem enviesadas.

Desse modo, na premissa de que estudos sobre influentes da Transparência Fiscal Ativa são relevantes, o presente estudo avança e se diferencia dos demais ao discutir a Transparência Fiscal Ativa sob a ótica da Gestão Fiscal dos recursos públicos. Essa lógica é explicada pelo fato de que a gestão fiscal representa as ações do gestor enquanto administrador dos recursos públicos, pois conforme explica Magalhães (2017), a gestão fiscal é o direcionamento de esforços para as atividades orçamentárias visando a análise, organização e administração de recursos, representando a atuação do gestor da coisa pública desde a confecção do orçamento até a prestação de contas de sua execução, dentro dos ditames legais. Sendo assim, como os resultados da gestão fiscal representam a atuação do gestor, este tende a dar maior transparência aos resultados positivos, conforme discorrem as teorias da Agência, da Escolha Pública e do Gerenciamento de Impressão, em sintonia.

Assim, o objetivo desta pesquisa é identificar se existe relação entre transparência fiscal ativa e gestão fiscal e como ocorre esta relação, nos municípios paraibanos.

Além do posto esta pesquisa se reveste de relevância, pois a transparência fiscal promove o fortalecimento do controle social e tem como objetivo o zelo pelo interesse coletivo, constituindo-se em um meio que permite a sociedade colaborar com o governo, participando e fiscalizando os atos da gestão pública, o que torna o entendimento dos fatores influentes da transparência fiscal uma necessidade (Mota, Diniz \& Santos, 2017)

Destaca-se a existência de limitações teóricas e instrumentais neste estudo, as quais devem ser levadas em consideração na análise de cenários complexos como Gestão Fiscal e Transparência Fiscal Ativa na gestão pública em virtude da impossibilidade de incorporação de todos os fatores que influenciam o tema.

\section{REFERENCIAL TEÓRICO}

\subsection{Transparência no Setor Público e seus conceitos}

Para uma participação mais efetiva no poder público, o cidadão necessita de informações relevantes para, por exemplo, escolher o gestor público que será responsável pela gerência dos recursos por ele aportado, conforme aponta Martins (2011). Neste sentido, o referido pesquisador deixa claro a essencialidade da disponibilização da informação no setor público, tendo em vista que a transparência é indispensável à promoção da cidadania e controle social. Complementando o assunto, Chen e Neshkova (2020) discorrem que profissionais e acadêmicos comungam do mesmo entendimento sobre a importância do aumento da transparência no âmbito público como meio de promoção de maior responsabilidade administrativa e combate a corrupção.

A transparência é definida por Ribeiro e Zuccolotto (2012, p. 5), "como o aumento do fluxo oportuno de informação econômica, social e política, segura, que é acessível para todos os cidadãos", sendo vista como aspecto central da democracia, em que a possibilidade de verificação independente e de acessar uma quantidade maior de informações em um menor número de docu- 
mentos, assim como o compromisso com a linguagem não arbitrária, podendo esses serem considerados seus aspectos mais importantes (Alt, Lassen \& Skilling, 2002).

Lewis (2011) distingue a transparência em dois tipos: ativa e passiva. No que tange o primeiro tipo, tem-se a divulgação sistemática e regular de informações governamentais, já o segundo tipo é o qual é requerido pelo cidadão, em que a administração pública deve atender ao pedido disponibilizando em tempo hábil o que foi solicitado, com exceção das informações confidenciais em detrimento da segurança nacional e de outros. Neste contexto, Mota, Diniz e Santos (2017, p. 294) entendem que a "transparência fiscal ativa consiste na divulgação franca, proativa, regular e sistemática, para toda a sociedade, de informações relacionadas a estrutura do governo, políticas fiscais, contas públicas e demais informações pertinentes ao bom controle social."

Neste prisma, diversos estudos foram realizados detendo como objetivo a análise da transparência governamental, como o de Santana Junior (2008) que buscaram analisar os níveis de transparência fiscal eletrônica observados nos sites dos Poderes/Órgãos dos estados e do Distrito Federal do Brasil e a sua associação com os seus respectivos indicadores econômico-sociais. Os resultados apontaram para a existência de relação entre os níveis de transparência fiscal eletrônica dos Poderes/Órgãos analisados e os seus respectivos indicadores econômico-sociais selecionados, com exceção dos Ministérios Públicos estaduais.

Em estudo buscando identificar quais fatores influenciam o nível de transparência eletrônica dos municípios brasileiros, Ribeiro e Zuccolotto (2012) concluíram que municípios com um maior volume de investimentos em saúde e educação tendem a ser mais transparentes, assim como que municípios com maior arrecadação tendem a disponibilizar mais informações à sociedade. Outro achado importante deste estudo é que o nível de transparência dos municípios se encontra alinhado ao nível de indicadores socioeconômicos, em que quanto melhor o indicador socioeconômico, melhor o nível de transparência do município.

Mota, Diniz e Santos (2017) pesquisaram sobre de que forma a execução orçamentária (receitas e gastos) influencia a Transparência Fiscal Ativa nos municípios do estado da Paraíba. Os resultados indicaram que as Receitas de Transferências, os Gastos com Saúde, a Receita Própria per capita e o Gasto com Pessoal se relacionam significativamente com a transparência fiscal Ativa dos municípios paraibanos, concluindo que a maioria das variáveis estudadas que compõem a estrutura orçamentária destes municípios, impacta na sua Transparência Fiscal Ativa.

Araújo et al. (2020) estudaram o nível de transparência pública das informações sobre os atos da gestão pública divulgados nos sítios eletrônicos dos entes municipais do Estado de Tocantins. Os resultados, de modo geral, evidenciaram que a observância à LAI, em média, foi melhor do que à LRF.

Gesuele e Matalo (2018) pesquisaram sobre a divulgação de informações via site, analisando uma amostra de 287 municípios italianos e espanhóis. Os achados demonstraram que fatores como visibilidade na Internet, riqueza e alavancagem, desempenham um papel importante para determinar o nível de divulgação eletrônica nestes países.

De Renzio e Wehner (2017) realizaram uma extensa revisão qualitativa da literatura de 38 pesquisas sobre abertura fiscal divulgados entre 1991 e início de 2015. A pesquisa evidenciou que maiores níveis de transparência orçamentária estão associados a um melhor desempenho fiscal, uma melhor governança e a resultados de desenvolvimento favoráveis.

Chen e Neshkova (2020) ao analisarem o efeito da transparência fiscal sobre a corrupção, em uma análise de painel cross-country, com dados de 95 países durante o período de 2006 a 2014, evidenciaram que países com maior transparência fiscal são percebidos como menos corruptos.

ElBerry e Goeminne (2020) estudaram os impactos das dimensões da transparência fiscal nos desvios de previsão do orçamento em países em desenvolvimento usando análise de regres- 
são. Os seus resultados lançaram luz e evidenciaram a importância de garantir a boa qualidade das informações divulgadas e a independência de órgãos de auditoria em países em desenvolvimento.

Assim, estes relatos empíricos demonstram a importância de se estudar a transparência no âmbito público, além de que evidenciam que os dispositivos legais não conseguem sozinhos garantir o nível de transparência nos entes públicos, evidenciando que outros fatores acabam por influenciar a disponibilidade de informações por parte dos órgãos públicos, sendo explicados também, por algumas teorias, como a Teoria da Agência, a Teoria da Escolha Pública e a Teoria do Gerenciamento de Impressão, as quais em conjunto, conseguem fornecer um direcionamento sobre o nível de assimetria informacional existente no âmbito público.

\subsection{Teoria da Agência, Teoria da Escolha Pública, Teoria do Gerenciamento de Impressão e a Transparência}

Os problemas de agência existem em todas as organizações, assim como em todos os esforços cooperativos, conforme destacado por Jensen e Meckling (1976), os quais definem a relação de agência como um contrato no qual o principal nomeia um agente para que este execute alguma atividade em seu nome, assim se ambos os lados forem maximizadores de utilidade, o agente tenderá a agir em benefício próprio em detrimento dos interesses do principal.

Pereira e Cordeiro (2012) explicam que o cidadão delega autoridade ao gestor público por intermédio do voto, que se constitui no instrumento utilizado para a escolha dos gestores. Assim, no âmbito público o cidadão/eleitor é o principal e o gestor público o agente, devendo o principal exigir contas do seu agente.

Neste cenário, a transparência informacional aparece como fator atenuante do problema de agência conforme explicam Alt, Lassan e Rose (2006), em que uma maior transparência se encontra ligada a redução da assimetria informacional, permitindo um maior monitoramento das ações do gestor público (agente) por parte do principal (eleitor/cidadão), auxiliando no processo de escolhas dos políticos.

Assim, nas pesquisas de divulgação voluntária de informação financeira no setor público, destaca-se a aplicação da Teoria da Agência (Alt, Lassen \& Shanna, 2006; Wehner \& De Renzio, 2013; Wright, 2013; Barros, 2014; Mota, Diniz \& Santos 2017), uma vez que segundo esta teoria, uma maior transparência das informações reduz a assimetria informacional e consequentemente o conflito de agência melhorando a qualidade da informação disponibilizada.

Outra teoria relacionada a transparência governamental é a Teoria da Escolha Pública, a qual procura examinar as interações organizacionais no âmbito da administração pública. Sanchez, Aceituno e Domínguez (2012) explicam que a teoria da escolha pública fornece um caminho alternativo para a complicada análise que rodeia a questão eleitoral, explicando como o governo toma suas decisões baseadas nas chances de reeleição, buscando ações que causem satisfação no cidadão/eleitor, ou seja, que aumente a quantidade de votos nas eleições. Barros (2014) salienta que a Teoria da Escolha Pública ao conseguir explicar de maneira mais profunda a relação entre agente e principal no âmbito público, complementa a Teoria da Agência, uma vez que a aplicação mais efetiva de transparência tende a diminuir a assimetria de informações e consequentemente minimizar os conflitos de interesses dos agentes públicos com a população.

Ainda sobre a teoria da escolha pública, Stiglitz (1999) esclarece que são dois os fatores que pesam contra a disponibilidade de informações: a) o ocultamento de falhas ou resultados ruins da gestão e b) a maior facilidade para o cometimento de fraudes e subornos. Dessa maneira, o referido pesquisador deixa claro a importância da análise de outros fatores, que não apenas os legais, uma vez que o nível de transparência das informações fiscais é afetado também por interesses próprios.

Meijer (2009) discorre que parte dos gestores públicos é contra a transparência das ações do governo, pelo fato de que ao divulgar determinadas informações, o cidadão que detém o poder de 
escolha possa vir a não eleger tal agente (gestor público) como seu representante. Destaca-se que tal pensamento converge para o que discorre a Teoria do Gerenciamento de Impressão.

A Teoria do Gerenciamento de Impressão se refere ao direcionamento de ações por parte de um indivíduo com o objetivo de moldar as percepções de si mesmo para os outros (Mohamend, Gardner \& Paolillo, 1999), complementando o que discorre a Teoria da Escolha Pública. Assim sob a ótica desta teoria o gestor público busca moldar a percepção que a sociedade tem de sua imagem através da manipulação de informações a respeito de suas ações. Neste contexto, Nobre (2017, p. 32) enfatiza que as informações orçamentárias e fiscais disponibilizadas pelos gestores públicos, tendem a se tornarem "comprometidas ou enviesadas, no intuito de ocultar falhas ou gastos indevidos, que prejudiquem a imagem do gestor, tornando a transparência nebulosa e comprometida."

Dentro deste contexto, estas teorias além de se complementarem, fornecem subsídios suficientes para um melhor entendimento do nível de transparência no setor público, ao explicarem que na busca por seus interesses pessoais, o gestor público tende a escolher ações que maximizem a sua reeleição ou mantimento de seu partido político no poder, direcionando esforços para o gerenciamento das informações que serão disponibilizadas ao cidadão, buscando transparecer informações positivas e que causem uma boa impressão.

\subsection{Gestão Fiscal e Hipóteses de Pesquisa}

Os pilares para uma boa gestão dos recursos públicos, assim como os mecanismos fiscais que regem o processo de gestão fiscal no Brasil são estabelecidos em diversas leis como a Lei n. ${ }^{\circ}$ 4.320/1964, a Constituição Federal de 1988 e a Lei Complementar n. .0101 de 2000 (LRF). No que tange a LRF, Magalhães (2017) destaca que o seu principal objetivo é o estabelecimento de regras de finanças públicas para os três níveis de governo, com foco em uma gestão fiscal transparente, de modo a minimizar riscos e reparar desvios que possam prejudicar o equilíbrio orçamentário.

Devido a sua importância, diversas pesquisas se propuseram a estudar a gestão fiscal no âmbito público como as de Kennedy e Robbins (2001) que buscaram investigar a determinação de regras fiscais na performance fiscal de países industrializados e as de Sarr (2015) que pesquisou sobre a relevância da determinação das regras e princípios que norteiam o processo orçamentário na execução fiscal em países africanos.

No âmbito brasileiro, pode-se destacar o estudo realizado por Cruz (2015) que analisou a relação entre os indicadores de cumprimento de limites e metas e a Gestão Fiscal, e; a pesquisa realizada por Magalhães (2017) que buscou analisar o efeito das características regionais na determinação da situação fiscal dos municípios e as diferenças regionais de gestão fiscal e seus fatores determinantes.

Do enfoque político processual, a gestão fiscal se inicia com a elaboração e aprovação do orçamento, e se estende até a prestação de contras do ente governamental por meio da elaboração dos demonstrativos contábeis (Hansen, Houlberg \& Pedersen, 2014). Sobre o tema, Magalhães (2017, p. 22) complementa que por "gestão fiscal, entendem-se as atividades voltadas para o orçamento com a finalidade de analisar, organizar e administrar os recursos do setor governamental", buscando o equilíbrio na execução orçamentária em que independentemente da realidade econômica ou gerencial, todos os entes públicos são obrigados a respeitar e cumprir os ditames da legislação fiscal.

Conforme definição, a gestão fiscal representa a atuação do gestor público no cumprimento de suas obrigações administrativas e legais, tendo em vista que abrange desde a confecção e aprovação do orçamento até a sua execução e consequente prestação de contas à sociedade.

Dessa maneira, conforme explicam as teorias da Agência, da Escolha Pública e do Gerenciamento de Impressão, os gestores tendem a dar maior transparência aos resultados de gestão fiscal positivos, se valendo da assimetria informacional que existe entre ele (gestor público) e o cidadão 
(eleitor) para gerenciar as informações a respeito de sua administração, ocasionando prejuízo no que tange a transparência das informações, uma vez que tais informações podem gerar a sua reeleição ou mesmo a condução do partido político do gestor público interessado.

Neste norte, a hipótese central desta pesquisa é a de que a Gestão Fiscal, que representa as ações do gestor da coisa pública no cumprimento de suas obrigações administrativas e legais, possui relação positiva com a Transparência Fiscal Ativa, sendo esta relação alicerçada na sinergia existente entre as Teorias da Agência, Escolha Pública e Gerenciamento de Impressão.

Destaca-se que para fazer uma boa gestão fiscal, os gestores públicos devem respeitar e obedecer aos ditames e limites legais impostos, o que proporciona a confecção de indicadores e índices de gestão fiscal que fornecem informações sobre as ações governamentais. Dessa maneira, a apresentação de índices em desacordo com os limites legais estabelecidos, representa uma má atuação do gestor público e, conforme as teorias da Agência, Escolha Pública e Gerenciamento de Impressão em sintonia explicam, o gestor público tende a gerenciar a transparência das informações a seu respeito.

Neste direcionamento, esta pesquisa utilizará como proxy para a gestão fiscal dos municípios estudados, o Índice Firjan de Gestão Fiscal (IFGF)², criado pela Federação da Indústria do Estado do Rio de Janeiro. Além disso, salienta-se que todos os indicadores que compõem o IFGF (Gasto com Pessoal, Investimento, Receita Própria, Custo da Dívida e Liquidez) se encontram em consonância com as diretrizes e limites legais definidos na LRF.

Dessa maneira, objetivando uma melhor apresentação dos resultados e tendo em vista o direcionamento das proxies para Gestão Fiscal, elaborou-se as seguintes hipóteses de pesquisa:

$\mathrm{H}_{1}$ : Relação positiva entre a Gestão Fiscal da Receita Própria melhor e o Índice de Transparência Fiscal Ativa dos municípios da Paraíba.

$\mathrm{H}_{2}$ : Relação positiva entre a Gestão Fiscal do Gasto com Pessoal e o Índice de Transparência Fiscal Ativa dos municípios da Paraíba.

$\mathrm{H}_{3}$ : Relação positiva entre a Gestão Fiscal do Investimento e o Índice de Transparência Fiscal Ativa dos municípios da Paraíba.

H4: Relação positiva entre a Gestão Fiscal da Liquidez e o Índice de Transparência Fiscal Ativa dos municípios da Paraíba.

H5: Relação positiva entre a Gestão Fiscal do Custo da Dívida e o Índice de Transparência Fiscal Ativa dos municípios da Paraíba.

\section{PROCEDIMENTOS METODOLÓGICOS}

\subsection{Amostra e Dados}

Para operacionalizar a busca da relação entre os indicadores da gestão fiscal e a transparência fiscal ativa nos municípios foram desenvolvidas e consequentemente testadas 5 hipóteses indicadas no item 2 a partir do teste de relação entre as variáveis da gestão fiscal representadas pelo índice Firjan de Gestão Fiscal (Receita Própria, Liquidez, Custo da Dívida, Gasto com pessoal e Investimento) e o Índice de Transparência Fiscal Ativa - ITFA. O recorte temporal da análise foi limitado pela disponibilidade de dados, permanecendo o período de 2013 a 2016.

O estado da Paraíba foi escolhido como base para esta pesquisa pelo fato de ter sido base de um trabalho conjunto de um Grupo formado pela Controladoria Geral da União (CGU), Tribunal de Contas do Estado da Paraíba (TCE/PB), Controladoria Geral do Estado (CGE), Ministério Público do Estado da Paraíba (MP/PB) e o Tribunal de Contas da União (TCU), o qual criou o Fórum

\footnotetext{
${ }^{2}$ A respeito da constituição dos itens que compõem o Índice Firjan de Gestão Fiscal - IFGF, destaca-se que toda metodologia envolvendo sua criação e obtenção valores para cada ente avaliado podem ser acessadas em: https://www.firjan.com.br/ifgf/
} 
Paraibano de Combate à Corrupção (FOCCO/PB), atuando no tema transparência nos Municípios paraibanos. Sendo assim, o FOCCO/PB desenvolveu o Índice de Transparência Fiscal Ativa - ITFA, que foi utilizado como variável dependente da variável Transparência Fiscal. A amostra partiu de um universo de 223 municípios que compõem o estado da Paraíba, dos quais após verificação dos dados válidos restaram 157, representando cerca de 70\% do total de municípios deste Estado.

O cômputo do índice de transparência tem como base uma métrica nacional de acordo com a realidade brasileira, contemplando as nuances e exigências legais, sendo obtido a partir do somatório de três componentes:

a) Conteúdo (C), que diz respeito as informações mínimas legalmente exigidas nos portais de transparência de cada ente analisado, com pontuação máxima no total de 1.650 pontos, perfazendo $60 \%$ do total.

b) Séries Históricas (SH), a qual é composta pela frequência que determinada informação é disponibilizada, com pontuação máxima no total de 200 pontos representando $7 \%$ do total.

c) Usabilidade (U), o qual trata da facilidade de acesso e navegação no portal de transparência de cada ente analisado, com pontuação máxima no total de 900 pontos, representando $33 \%$ do total.

Assim, chega-se a nota total da transparência 2.750 pontos dada pelo somatório de: C máx + SH máx + U máx $=100 \% .^{3}$

Como variável dependente representante da Gestão Fiscal a presente pesquisa se utilizará do Índice Firjan de Gestão Fiscal nas suas dimensões: Receita Própria, Liquidez, Custo da Dívida, Gastos com Pessoal e Investimento. Destaca-se que a pontuação varia de 0 a 1, e quanto mais próximo de 1 melhor o nível da Gestão Fiscal do ente público. Além da nota atribuída os indicadores são classificados em quatro conceitos:

- $\quad$ Conceito A (Gestão de Excelência): resultados superiores a 0,8 pontos.

- $\quad$ Conceito B (Boa Gestão): resultados compreendidos entre 0,6 e 0,8 pontos.

- $\quad$ Conceito C (Gestão em Dificuldade): resultados compreendidos entre 0,4 e 0,6 pontos.

- $\quad$ Conceito D (Gestão Crítica): resultados inferiores a 0,4 pontos.

Como variáveis de controle, optou-se por utilizar a população estimada e o nível de desenvolvimento socioeconômico de cada município. Quanto a população estimada a qual representa a dimensão dos municípios estudados, destaca-se sua utilização em algumas pesquisas como as realizadas por Leite Filho, Andrade e Colares (2014) e Marques (2014) as quais evidenciaram uma relação positiva com o nível de transparência pública. Dessa maneira, nesta pesquisa será utilizado o logaritmo natural da população estimada de cada município (POP) como variável de controle, obtida na base de dados do IBGE.

O nível de desenvolvimento socioeconômico dos municípios será representado pelo Índice Firjan de Desenvolvimento Municipal (IFDM), obtido na base de dados do Sistema Firjan de Desenvolvimento Municipal. Sobre essa variável tem-se que Comin et al. (2016) e Leite Filho, Andrade e Colares (2014) relataram em suas pesquisas uma relação positiva com a transparência das informações no âmbito público. O IFDM é composto por três áreas: Emprego \& Renda, Educação e Saúde, possuindo leitura idêntica ao IFGF, o qual varia de 0 a 1, em que quanto mais próximo de 1 maior é o desenvolvimento do município.

\footnotetext{
${ }^{3}$ A respeito da constituição dos itens que compõem o Índice de transparência Fiscal Ativa - ITFA, destaca-se que toda metodologia envolvendo sua criação e obtenção de nota final para cada ente avaliado, se encontra disponível no site do Tribunal de Contas da Paraíba - TCE/PB no endereço: http://tce.pb.gov.br/indice-de-transparencia-publica/itensavaliados.
} 
Dessa maneira, espera-se uma relação positiva entre o nível populacional e o desenvolvimento socioeconômico dos municípios paraibanos e seu respectivo Índice de transparência Fiscal Ativa.

\subsection{Operacionalização Metodológica e Tratamento Estatístico dos Dados}

Primeiramente coletou-se os dados referentes a variável ITFA dos municípios paraibanos dispostos nos Relatórios de Transparência Pública da FOCCO/PB, e em seguida os dados referentes as demais variáveis independentes foram coletadas na base de dados da FIRJAN. A relação entre a variável dependente (ITFA) e as variáveis independentes (IFGFRP, IFGFGP, IFGFINV, IFGFLQ e IFGFCD) foi estimada em painel de dados pooled ordinary least squares (POLS), uma vez que as características dos dados indicaram este estimador estatístico como o mais apropriado. As variáveis de controle foram obtidas na base de dados do IBGE e do FIRJAN, para a variável população e IFDM respectivamente. Dessa maneira o modelo estatístico utilizado foi o seguinte:

ITF $A_{i t}=\beta_{0}+\beta_{1} I F G F R P i t+\beta_{2} I F G F G P_{s i t}+\beta_{3} I F G F L Q_{i t}+\beta_{4} I F G F I N V_{i t}+\beta_{5} I F G F C D_{i t}+\beta_{6} P O P_{i t}$ $+\beta 7$ IFDM $M_{i t}+\mu_{i t}$.

Onde:

ITFA - Índice de Transparência Fiscal Ativa;

IFGFRP - Índice Firjan de Gestão Fiscal Receita Própria;

IFGFGP - Índice Firjan de Gestão Fiscal Gasto Com Pessoal;

IFGFLQ - Índice Firjan de Gestão Fiscal Liquidez;

IFGFINV - Índice Firjan de Gestão Fiscal Investimento;

IFGFCD - Índice Firjan de Gestão Fiscal Custo da Dívida;

$P O P$ - Logaritmo natural da população estimada de cada município;

IFDM - Índice Firjan de Desenvolvimento Municipal;

i-municípios brasileiros;

t-anos;

$\mu i t$ - erros.

\section{APRESENTAÇÃO E ANÁLISE DOS RESULTADOS}

\subsection{Estatística Descritiva das Variáveis}

Na tabela 1 é possível observar a estatística descritiva referente aos municípios paraibanos que compõem a amostra, no que tangem as variáveis independente e dependente.

Tabela 1 - Estatística descritiva das Variáveis Dependente e Independentes.

\begin{tabular}{cccccc}
\hline Variável & Observações & Média & Desvio Padrão & Mínimo & Máximo \\
\hline ITFA & 604 & 5,59 & 1,89 & 0 & 9,9 \\
IFGFRP & 604 & 0,12 & 0,11 & 0,01 & 0,75 \\
IFGFGP & 604 & 0,26 & 0,27 & 0 & 0,92 \\
IFGFINV & 604 & 0,35 & 0,23 & 0 & 1 \\
IFGFLQ & 604 & 0,39 & 0,33 & 0 & 1 \\
IFGFCD & 604 & 0,78 & 0,17 & 0 & 1 \\
POP & 604 & 21.084 & 71.786 & 0,753 & 791.438 \\
IFDM & 604 & 0,60 & 0,06 & 0,41 & 0,79 \\
\hline
\end{tabular}

Fonte: Dados da pesquisa.

Os resultados apontam para uma gestão crítica (conceito D) para a maioria dos indicadores, excerto o referente ao Custo da Dívida, o qual obteve conceito B (Boa Gestão), com destaque para o baixo grau de endividamento dos municípios paraibanos. Ademais, os resultados das estatísticas 
descritivas evidenciam municípios dependentes de transferências de recursos de outros entes, com um gasto com pessoal as margens do limite estabelecido pela LRF, com baixo nível de investimento, provavelmente devido ao gasto elevado com o pessoal e com a liquidez comprometida por postergação de dívidas de curto prazo.

Quanto a população residente dos municípios paraibanos, observa-se um alto grau de heterogeneidade entre os municípios, uma vez que existem municípios com menos de dois mil habitantes e outros com mais de setecentos mil. O nível médio de desenvolvimento dos municípios paraibanos é regular, sendo este um resultado observado na grande maioria dos municípios da região Nordeste (FIRJAN, 2017).

Para um melhor exame será analisada a evolução média dos indicadores de transparência e Gestão Fiscal dos municípios paraibanos.

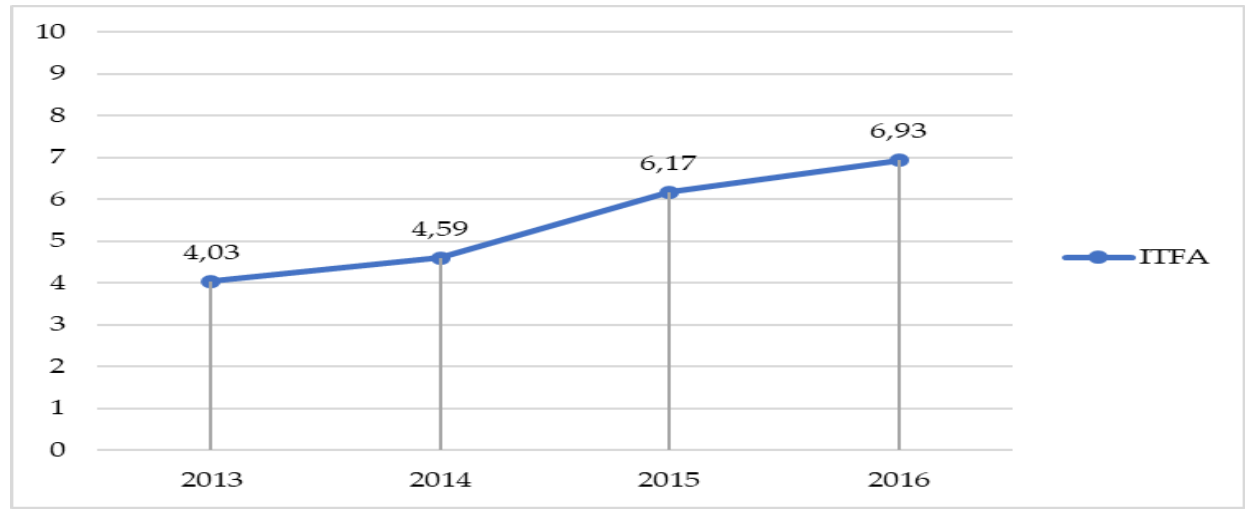

Figura 01 - Evolução temporal média do ITFA

Fonte: Dados da Pesquisa

Conforme se observa, há uma tendência de melhoramento na Transparência Fiscal Ativa nos municípios paraibanos, a qual pode ser ocasionada pela maior efetividade dos dispositivos legais, assim como dos órgãos de controle. Entretanto, mesmo com a melhoria no ITFA, ainda se observa um ambiente com forte assimetria informacional. Estes dados convergem para os achados nos estudos de Wright (2013) e Mota, Diniz e Santos (2017), apontando para uma necessidade de aprimoramento no processo de divulgação das informações públicas.

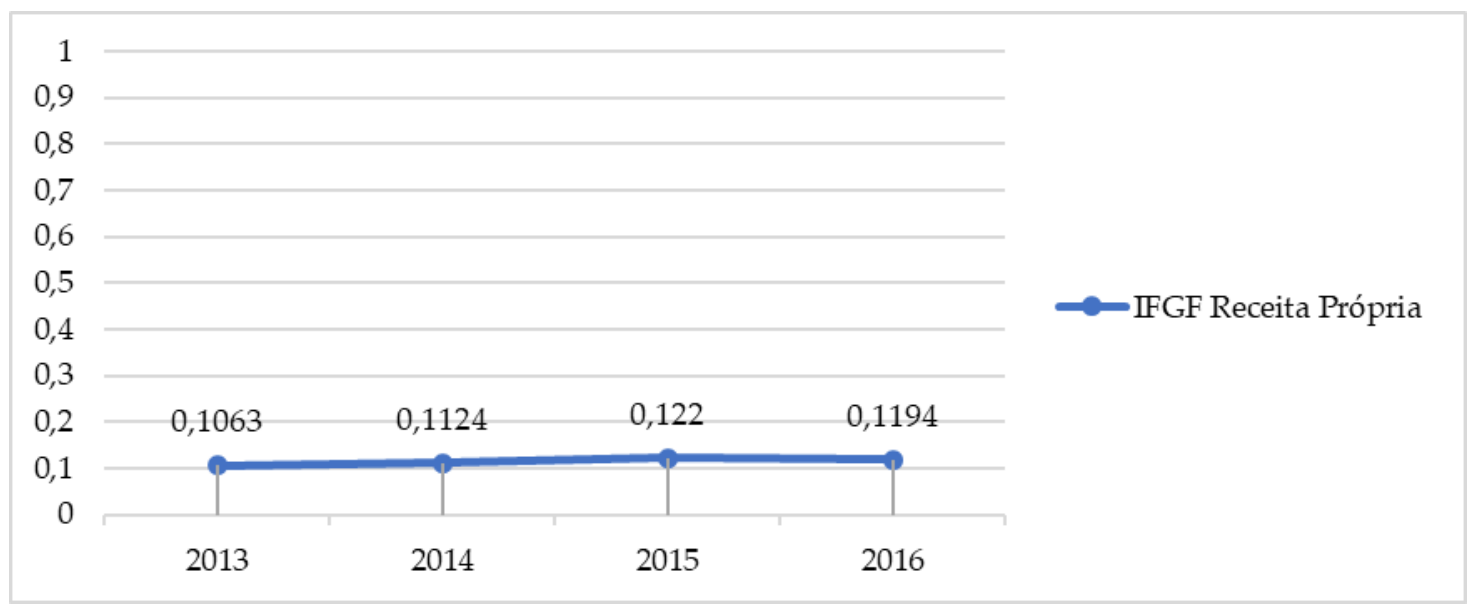

Figura 02 - Evolução temporal média do IFGF Receita Própria Fonte: Dados da Pesquisa (2018)

Conforme se evidencia, há uma tênue tendência de melhoramento na geração de receitas próprias nos municípios paraibanos, entretanto os dados corroboram para um baixo nível neste 
indicador, tendo em vista que a média durante a análise temporal fica estagnada no conceito D (Gestão Crítica), o que revela municípios sensivelmente dependentes de transferências constitucionais e voluntárias de recursos de outros entes (Estadual e Federal). Este resultado é algo preocupante, tendo em vista que as transferências fiscais estão ligadas ao desestímulo da arrecadação tributária local, a redução da responsabilidade fiscal e consequentemente a baixa transparência fiscal (Wyckoff, 1988; Strumpf, 1998).

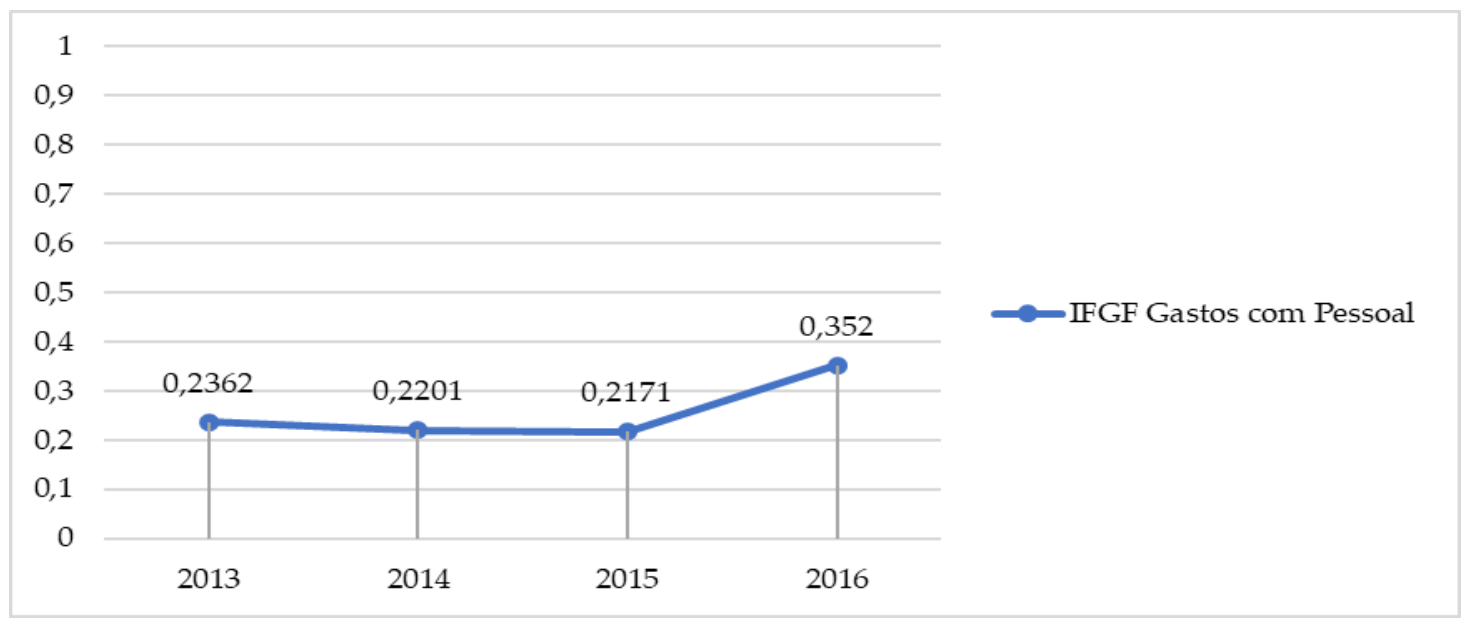

Figura 03 - Evolução temporal média do IFGF Gasto com Pessoal Fonte: Dados da Pesquisa

A gestão fiscal do gasto com pessoal apresentou municípios com orçamento comprometidos por este tipo de gasto, uma vez que este indicador apresentou conceito D (Gestão Crítica), ou seja, a maioria dos municípios ou já passaram o limite legal (60\% da RCL) imposto pela LRF ou se encontram no limite prudencial ( $57 \%$ da RCL). Destaca-se que se o crescimento deste tipo de gasto continuar, maiores percentuais de receitas serão comprometidos o que poderá resultar em restrições fiscais e penalidades impostas pela Lei de Responsabilidade Fiscal. Sobre o tema, cabe realçar que o FIRJAN (2017) evidenciou um crescimento de 6,7\% de 2013 a 2016 nos municípios brasileiros, o que demonstra que este tipo de gasto vem crescendo em todo território nacional.

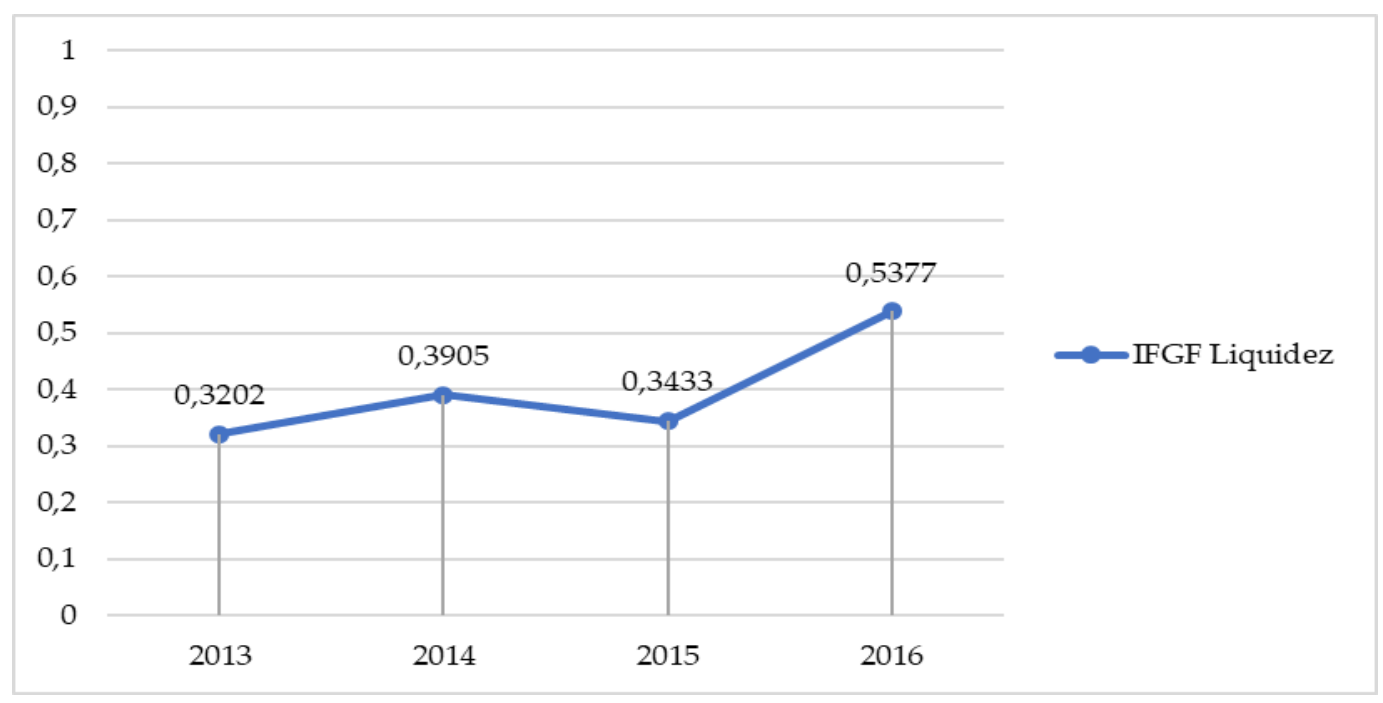

Figura 04 - Evolução temporal média do IFGF Liquidez Fonte: Dados da Pesquisa 
A gestão fiscal da liquidez, apresentou uma melhoria de 2015 para 2016, passando do conceito D (Gestão Crítica) para o conceito C (Gestão em Dificuldades), o que demonstra um esforço do gestor público em deixar os entes municipais com recursos em caixa suficientes para cobrir as despesas postergadas. Apesar desta melhora neste indicador, tem-se que a postergação de Despesas via Restos a Pagar tem sido a principal fonte de financiamento e ajuste dos orçamentos no âmbito das despesas públicas governamentais brasileiras, o que influencia fortemente para o baixo desempenho neste indicador (FIRJAN, 2017).

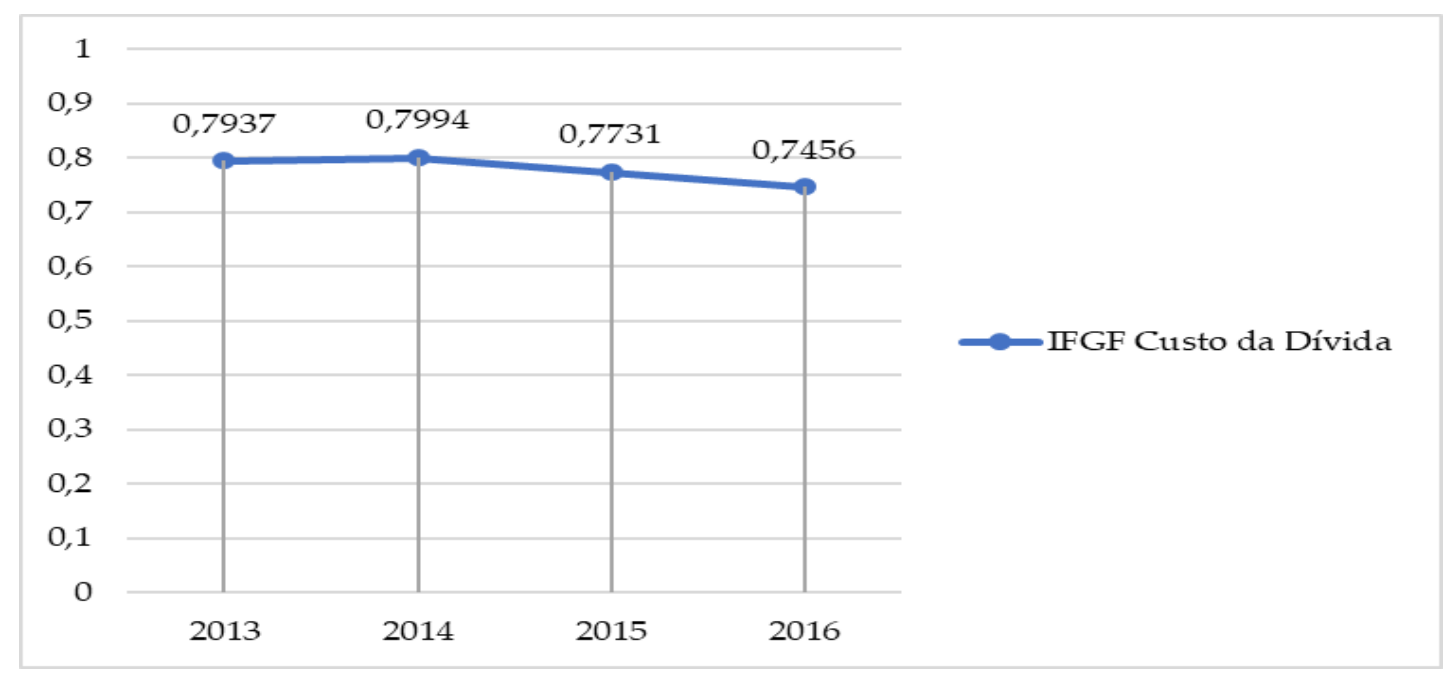

Figura 05 - Evolução temporal média do IFGF Custo da Dívida

Fonte: Dados da Pesquisa

Os dados demonstram uma boa gestão fiscal do Custo da Dívida, o qual detém conceito B (Boa Gestão) durante todo recorte temporal. Assim, a Gestão Fiscal do Custo da Dívida não tem sido problema para os entes municipais paraibanos, destacando ainda que cerca de 3.935 dos municípios brasileiros declararam não possuir dívidas (FIRJAN, 2017).

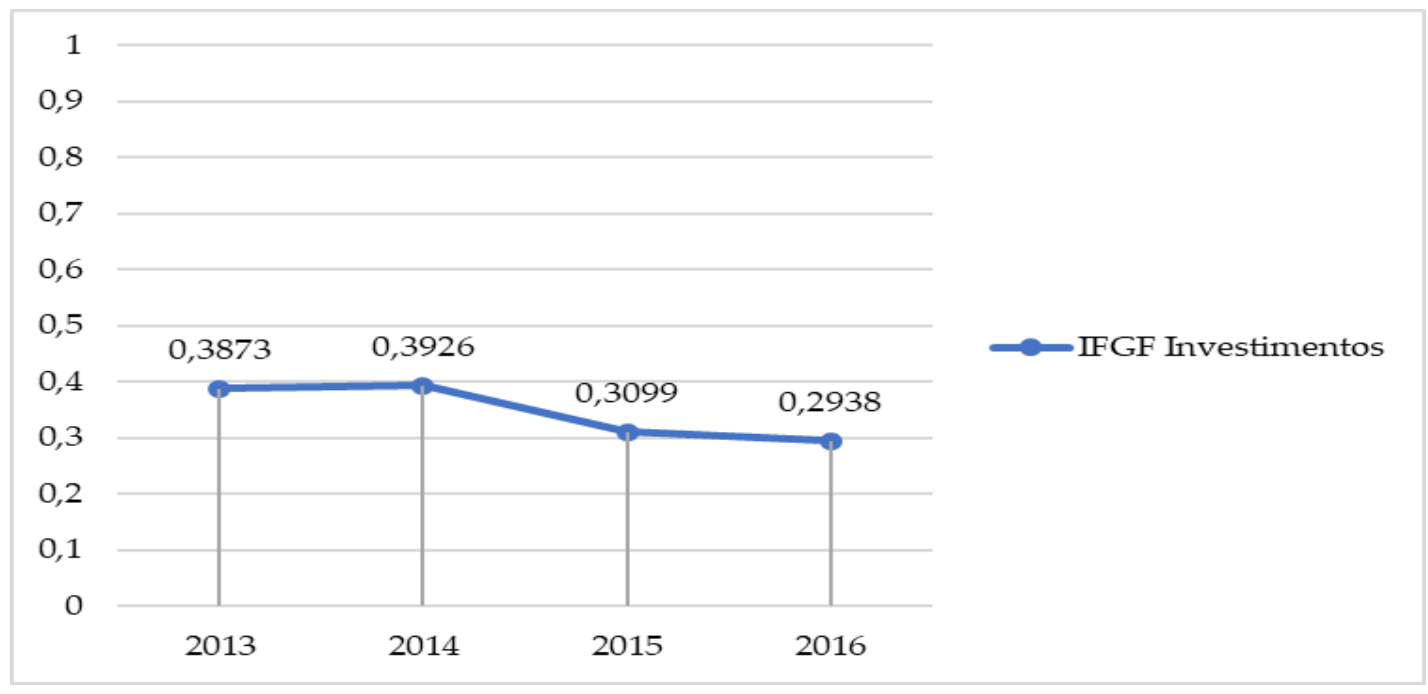

Figura 06 - Evolução temporal média do IFGF Investimentos Fonte: Dados da Pesquisa

Os municípios paraibanos demonstraram uma Gestão Crítica (Conceito D) durante todo recorte temporal do indicador de gestão fiscal dos Investimentos, o qual apresentou uma queda nos 
anos de 2015 e 2016, fato este devido provavelmente ao comprometimento dos entes municiais com despesas obrigatórias. Assim, evidencia-se um baixo comprometimento do orçamento dos entes públicos com este tipo gasto destinado ao fornecimento de bens de infraestrutura em bom estado de funcionamento. Em comparação, no âmbito nacional, destaca-se que os investimentos públicos atingiram seu menor nível em 10 anos, por exemplo, em 2016 os municípios deixaram de investir 7,5 bilhões em referência ao ano de 2015 (FIRJAN, 2017).

\subsection{Testes de Hipóteses}

O teste das hipóteses deste estudo foi realizado a partir da estimação do modelo empírico definido na equação (1). Antes de sua estimação, no entanto, foi verificado através do coeficiente de correlação de Pearson ( $r$ ), a correlação entre as variáveis em estudo, detendo como objetivo a verificação de possível correlação elevada entre as variáveis explicativas, fato que pode trazer viés para os parâmetros do modelo. Os resultados estão dispostos na Tabela 2 e não apontam para correlação elevada entre as variáveis explicativas.

Tabela 2 - Correlação de Pearson entre as variáveis do modelo

\begin{tabular}{|c|c|c|c|c|c|c|c|c|}
\hline & ITFA & IFGFRP & IFGFGP & IFGFINV & IFGFLQ & IFGFCD & POP & IFGM \\
\hline ITFA & 1,0000 & & & & & & & \\
\hline IFGFRP & $0,1291^{* * *}$ & 1,0000 & & & & & & \\
\hline IFGFGP & 0,0289 & $0,1062^{* *}$ & 1,0000 & & & & & \\
\hline IFGFINV & $0,0922^{* *}$ & 0,0403 & $0,3058^{* * *}$ & 1,0000 & & & & \\
\hline IFGFLQ & $0,1538^{* * *}$ & $0,0481^{*}$ & $0,0947^{* *}$ & 0,0118 & 1,0000 & & & \\
\hline IFGFCD & $0,0804^{* *}$ & 0,0250 & $0,1062^{* *}$ & $0.0966^{* *}$ & $0.0981^{* *}$ & 1,0000 & & \\
\hline POP & $0,1329^{* * *}$ & $0,6280^{* * *}$ & 0,0180 & 0,0407 & 0,0008 & 0,0014 & 1,0000 & \\
\hline IFGM & $0,1440^{* * *}$ & $0,3456^{* * *}$ & 0,0043 & 0,0616 & 0,0302 & 0,0495 & 0,3157 & 1,0000 \\
\hline
\end{tabular}

Para se auferir mais precisamente o relacionamento existente entre as variáveis e assim testar as hipóteses de pesquisa, foi utilizada, além da Correlação de Pearson, a análise de dados em painel ou dados longitudinais através de uma regressão múltipla. Essa análise é caracterizada por possuir observações em duas dimensões, ou seja, o tempo e o espaço.

Com a finalidade de averiguar qual é o tipo de regressão mais adequada para a estimação, entre o Modelo Pooled OLS e o Modelo de Efeitos Fixos realizou-se o teste de Chow, que possui as seguintes hipóteses: H0: modelo pooled e H1: modelo de efeitos fixos (irrestrito) (Wooldridge, 2002). Por intermédio do resultado do teste $(0,598)$ a nível de significância de $5 \%$, observou-se a não rejeição da hipótese nula. Posteriormente fez-se o teste de Breusch-Pagan para avaliar a possibilidade de utilizar modelo aleatório, o qual a nível de $5 \%$ de significância não foi validado $(1,00)$, desse modo, com base nos testes realizados que indicaram a escolha da modelagem por pooled OLS, serão analisados os resultados referentes a este modelo estimado (Tabela 3), mais especificamente as influentes relacionadas com a transparência fiscal ativa dos municípios paraibanos.

Para um melhor estudo sobre a Transparência Fiscal Ativa dos municípios paraibanos, os dados foram defasados em 1 e 2 anos, tendo em vista analisar os efeitos da disponibilidade tardia das informações em sintonia com a Teoria do Gerenciamento de Impressão. Para uma maior robustez dos resultados, o TOBIT foi estimado, mantendo-se os mesmos resultados da estimação do MQO. 
Tabela 3 - Estimação do Modelo

\begin{tabular}{|c|c|c|c|c|}
\hline Variáveis & $\begin{array}{l}\text { Modelo } 1 \mathrm{MQO} \\
\text { Sem defasagem }\end{array}$ & $\begin{array}{l}\text { Modelo } 2 \text { MQO Com } \\
\text { defasagem } 1 \text { ano }\end{array}$ & $\begin{array}{l}\text { Modelo } 3 \text { MQO Com } \\
\text { defasagem } 2 \text { anos }\end{array}$ & Modelo 4 TOBIT \\
\hline Constante & $\begin{array}{c}2,7911^{* *} \\
(0,047)\end{array}$ & $\begin{array}{c}5,0555^{* * *} \\
(0,000)\end{array}$ & $\begin{array}{r}1,2128 \\
(0,392) \\
\end{array}$ & $\begin{array}{c}4,2047^{* * *} \\
(0,000)\end{array}$ \\
\hline IFGFRP & $\begin{array}{l}0,6315 \\
(0,548) \\
\end{array}$ & $\begin{array}{l}1,5154 \\
(0,159) \\
\end{array}$ & $\begin{array}{c}-1,7756^{*} \\
(0,095)\end{array}$ & $\begin{array}{c}0,70254 \\
(0,447) \\
\end{array}$ \\
\hline IFGFGP & $\begin{array}{l}0,5631^{*} \\
(0,073) \\
\end{array}$ & $\begin{array}{c}-0,7861^{* *} \\
(0,014) \\
\end{array}$ & $\begin{array}{c}-0,5702^{*} \\
(0,073) \\
\end{array}$ & $\begin{array}{r}0,39257 \\
(0,188) \\
\end{array}$ \\
\hline IFGFINV & $\begin{array}{c}-0,78021^{* *} \\
(0,026)\end{array}$ & $\begin{array}{c}0,8123^{* *} \\
(0,023)\end{array}$ & $\begin{array}{c}1,7303^{* * *} \\
(0,000)\end{array}$ & $\begin{array}{c}-0,75262^{* *} \\
(0,034)\end{array}$ \\
\hline IFGFLQ & $\begin{array}{c}0,8472^{* * *} \\
(0,000)\end{array}$ & $\begin{array}{l}-0,3110 \\
(0,180) \\
\end{array}$ & $\begin{array}{l}-0,0820 \\
(0,720) \\
\end{array}$ & $\begin{array}{c}0,89187^{* * *} \\
(0,000)\end{array}$ \\
\hline IFGFCD & $\begin{array}{c}-0,9662^{* *} \\
(0,037) \\
\end{array}$ & $\begin{array}{l}0,2258 \\
(0,632)\end{array}$ & $\begin{array}{l}0,5948 \\
(0,203) \\
\end{array}$ & $\begin{array}{c}-1,1122^{* *} \\
(0,015)\end{array}$ \\
\hline POP & $\begin{array}{l}0,1295 \\
(0,268) \\
\end{array}$ & $\begin{array}{l}0,0365 \\
(0,760) \\
\end{array}$ & $\begin{array}{c}0,2477^{* *} \\
(0,036)\end{array}$ & $\begin{array}{l}1,8500 \\
(0,178) \\
\end{array}$ \\
\hline IFGM & $\begin{array}{c}3,4343^{* * *} \\
(0,008)\end{array}$ & $\begin{array}{l}-0,1676 \\
(0,899) \\
\end{array}$ & $\begin{array}{l}2,3842^{*} \\
(0,069)\end{array}$ & $\begin{array}{c}3,1672^{* *} \\
(0,017)\end{array}$ \\
\hline $\mathrm{N}$ & 604 & 603 & 602 & 604 \\
\hline $\mathrm{R}^{2}$ & 0,070 & 0,031 & 0,05 & \\
\hline $\begin{array}{l}\mathrm{R}^{2} \mathrm{aj} \\
\text { P-value } \\
(\mathrm{F})\end{array}$ & $\begin{array}{l}0,059 \\
0,000\end{array}$ & $\begin{array}{l}0,020 \\
0,007\end{array}$ & $\begin{array}{l}0,04 \\
0,00\end{array}$ & \\
\hline \multicolumn{2}{|c|}{ Teste Chow ( $p$-valor) } & \multicolumn{3}{|l|}{0,598} \\
\hline \multicolumn{2}{|c|}{ Breusch Pagan (p-valor) } & \multicolumn{3}{|l|}{1,0000} \\
\hline \multicolumn{2}{|c|}{ Teste de White (p-valor) } & \multicolumn{3}{|l|}{0,677} \\
\hline \multicolumn{2}{|c|}{ Jarque-Bera ( $p$-value $)$} & 0,000 & & \\
\hline
\end{tabular}

Fonte: Dados da pesquisa.

Notas: Entre parênteses encontram-se as estatísticas t. Significativo a 1\%; **: Significativo a 5\%; **; Significativo a $10 \%$. Para detectar a presença de multicolinearidade fez-se uso dos testes FIV (variance inflation factor, obtendo-se um FIV 1,51 e concluindo pela existência tolerável de colinearidade (Levine, Berenson, \& Stephan, 2000). Erros-padrão estimados sem correção para heterocedasticidade de White $(0,677)$, uma vez que a hipótese nula de variâncias homocedásticas não foi rejeitada. De acordo com o teorema do limite central e considerando que foram utilizadas 604 observações, o pressuposto da normalidade pode ser relaxado (Brooks, 2002).

Conforme Tabela 3, os resultados são distintos para alguns dos índices de Gestão Fiscal. Assim ao se estimar a $\mathrm{H}_{1}$ mensurada pela variável IFGFRP, destaca-se que esta não se apresentou estatisticamente significante, isto é, pode ser rejeitada. Desse modo o nível de Gestão Fiscal no que tange as Receitas Próprias dos municípios paraibanos não apresentam relação significante com o nível da Transparência Fiscal Ativa. Esse resultado pode ser decorrente do baixo nível de geração de receita própria dos municípios estudados. Destaca-se que quando os dados são analisados na perspectiva de efeito defasado em 2 anos, a relação entre as variáveis ganha significância estatística com sinal negativo, indicando que piores resultados no passado geram uma maior transparência no presente, o que converge para as Teorias da Agência, Escolha Pública e Gerenciamento de Impressão, uma vez que bons resultados no presente geram uma imagem positiva da gestão, fazendo com que o gestor público busque uma maior transparência dessas informações no intuito de compensar os fracos resultados do passado.

Quanto a $\mathrm{H}_{2}$, observou-se uma relação positiva e significativa a nível de $10 \%$, entre a variável IFGFGP e o nível de Transparência Fiscal Ativa, indicando que melhores índices de Gestão Fiscal referente ao Gasto com Pessoal estão relacionados com maiores índices de transparência das informações no âmbito público indo ao encontro das teorias da Agência, Escolha Pública e Geren- 
ciamento de Impressão. Destaca-se que estes resultados vão na direção contrária dos achados empíricos do trabalho de Mota, Diniz e Santos (2017) e convergem para os apresentados por Boubeta, Santias e Alegre (2010) que concluíram em sua pesquisa que quanto maior o Gasto com Pessoal menor o índice de Transparência Fiscal Ativa. Entretanto, quando se analisa os resultados levando em consideração as variáveis defasadas em 1 e 2 anos, a relação entre as variáveis torna-se negativa, indicando que quanto pior foi o gasto com pessoal no passado maior será a divulgação deste tipo de informação no presente. Assim, ao se analisar tais informações pela ótica das teorias apresentadas, estes resultados levam ao entendimento de que quando se obtém resultados melhores no presente, uma maior transparência é dada a estas informações como tentativa de ofuscar os resultados inferiores obtidos no passado.

No que tange a hipótese $\mathrm{H}_{3}$ que afirma a existência de relação positiva entre a Gestão Fiscal em relação ao Investimento e o Índice de Transparência Fiscal Ativa dos municípios da Paraíba, tem-se que apesar de apresentar significância estatística, não apresentou o sinal esperado, o que leva a sua rejeição. Todavia, ao se considerar os efeitos da defasagem de 1 e 2 anos respectivamente, tem-se uma mudança no padrão da hipótese e esta não pode ser rejeitada. Quanto a esses achados, pode-se inferir que, no curto prazo, as obras de infraestrutura ainda estão em andamento fazendo com que o gestor não dê tanta divulgação à informação, todavia com o término da obra, uma maior publicidade das informações é dada, podendo ser explicada pelas Teorias da Agência, Escolha Pública e Gerenciamento de Impressão, pois conforme explicam estas teorias em sintonia, o gestor tenderá a proporcionar uma maior transparência das informações positivas a seu respeito, visando manter-se no poder e/ou manter seu grupo político.

Ao mensurar a hipótese $\mathrm{H}_{4}$, a qual prevê relação positiva entre a Gestão Fiscal em relação a Liquidez e o Índice de Transparência Fiscal Ativa dos municípios da Paraíba, tem-se uma relação positiva e significante o que leva a sua não rejeição. Neste sentido, o pagamento de dívidas no prazo gera uma maior transparência, uma vez que a imagem de uma gestão boa pagadora é transmitida, convergindo com que o discorrem as Teorias da Agência, Escolha Pública e Gerenciamento de Impressão. Destaca-se que quando se considera os efeitos de defasagem de 1 e 2 anos a significância é perdida.

Quanto a hipótese $\mathrm{H}_{5}$, que trata do Custo da Dívida, prevendo uma relação positiva entre a Gestão Fiscal em relação a esta variável e o Índice de Transparência Fiscal Ativa dos municípios da Paraíba, tem-se uma relação significante e negativa, o que ocasiona a sua rejeição. Estes resultados podem advir do baixo nível de endividamento dos municípios. Ao se considerar o efeito da defasagem de 1 e 2 anos, constata-se a perca de significância.

As variáveis de controle demonstraram resultados divergentes. Assim, quanto a relação entre o nível populacional e a Transparência Fiscal Ativa tem-se que não se mostrou significante divergindo dos estudos empíricos apresentados (Leite Filho, Andrade e Colares 2014; Marques 2014). Em relação ao IFDM, observa-se uma relação positiva e significante, convergindo com os relatos empíricos apresentados (Leite Filho, Andrade e Colares 2014; Comin et al. 2016), indicando que melhores níveis de desenvolvimento socioeconômico nos municípios estão positivamente relacionados com o nível de transparência fiscal ativa.

De maneira geral, os resultados dos testes de hipóteses revelam que a transparência ativa das informações sobre a gestão fiscal dos entes públicos, que representa a atuação do gestor da coisa pública no cumprimento de suas obrigações administrativa e legais, tende a se tornar enviesada, pois conforme os dados demonstraram, um maior nível de transparência é dado aos resultados positivos em detrimento dos resultados negativos, o que contraria as leis e normas instituídas.

Em sintonia, as teorias da Agência, Escolha Pública e Gerenciamento de Impressão explicam estes resultados, ao esclarecer que na busca por seus interesses pessoais, o gestor público tende a escolher ações que maximizem a sua reeleição ou recondução de seu partido político no po- 
der, emanando esforços para o gerenciamento das informações que serão disponibilizadas à sociedade, dando maior transparência as informações positivas e que causem uma boa impressão sua e da sua gestão e ocultando as informações negativas. Estes achados convergem e complementam a literatura sobre transparência no âmbito público, ao demonstrar empiricamente que outros fatores além de leis e normas influenciam o nível de transparência pública.

\section{CONSIDERAÇÕES FINAIS}

A presente pesquisa objetivou identificar se existe relação entre transparência fiscal ativa e gestão fiscal e como ocorre esta relação nos municípios paraibanos. Desse modo, ao analisar a qualidade da Gestão Fiscal dos municípios paraibanos, constatou-se que a maioria dos municípios obtiveram nota D (Gestão Crítica) em relação a maioria dos indicadores (Liquidez, Receita Própria, Gasto Com Pessoal e Investimento) e nota B (Boa Gestão) no que tange o Custo da Dívida.

Ao se analisar os dados sobre lente conjunta das Teorias da Agência, Escolha Pública e Gerenciamento de Impressão, tem-se informações relevantes deste tema tão dinâmico, uma vez que os dados sinalizam para o fato de que na busca dos interesses pessoais, o agente público com o objetivo de se manter no poder, assim como o de manter seu partido político, acaba desrespeitando as regras legais em prol do gerenciamento de sua imagem, mesmo que isto o deixe suscetível de ser penalizado com multas e até com penalidades mais duras como a inelegibilidade.

De maneira geral, os resultados apontam para municípios sensivelmente dependentes de transferências de recursos de outros entes (Estadual e Federal), com baixo nível de investimentos em infraestrutura devido ao grande volume de gastos com pessoal e que postergam dívidas de curto prazo comprometendo sua liquidez, mas com uma boa gestão do custo da dívida, um nível de desenvolvimento socioeconômico regular e com níveis populacionais bastante heterogêneos.

Quanto a Transparência Fiscal Ativa, observou-se a existência de uma tendência de melhoria, que pode ser ocasionada pela maior efetividade dos dispositivos legais, assim como dos órgãos de controle. Entretanto, mesmo com a melhoria no ITFA, ainda se observa um ambiente com relevante assimetria informacional, apontando para uma necessidade de aprimoramento no processo de divulgação das informações públicas.

Ao se analisar as hipóteses, averiguou-se relação estatística, significante e com o sinal esperado para $\mathrm{H}_{2}$ e $\mathrm{H}_{4}$ indicando que maiores índices de Gestão Fiscal dos Gastos com Pessoal e Liquidez, estão positivamente relacionados a maiores níveis de Transparência Fiscal Ativa. A hipótese $\mathrm{H}_{1}$ não se mostrou significante o que levou a sua rejeição. As hipóteses $\mathrm{H}_{3}$ e $\mathrm{H}_{5}$ apesar de demonstrarem significância estatística, não apresentaram a relação esperada, o que gerou a rejeição de ambas.

Quando considerado o efeito da defasagem, as hipóteses $\mathrm{H}_{1}$ e $\mathrm{H}_{2}$ apresentaram relação negativa. Assim, ao se analisar tais evidências pela ótica das teorias da Agência, Escolha Pública e Gerenciamento de Impressão, estes resultados levam ao entendimento de que quando se obtém resultados melhores no presente, uma maior transparência é dada a estas informações como tentativa de ofuscar os resultados inferiores obtidos no passado. No que diz respeito a hipótese $\mathrm{H}_{3}$, quando considerada a defasagem de 1 e 2 dois anos, obtém-se relação positiva com significância estatística e não se pode rejeitá-la. Os resultados quanto a esta hipótese sugerem que os investimentos públicos recebem um maior nível de transparência apenas quando concluídos, ou seja, a construção de um hospital por exemplo, só receberá a devida divulgação quando for concluído.

De maneira geral, as evidências apresentadas nesta pesquisa contribuem para a academia ao destacar que resultados positivos de gestão fiscal estão relacionados com maior nível de transparência fiscal ativa nos municípios paraibanos, o que evidencia que as leis e normas não garantem, sozinhas, o nível adequado de transparência. Destaca-se ainda que estes achados vão ao encontro com o que explicam as teorias da Agência, da Escolha Pública e do gerenciamento de Im- 
pressão, em sintonia, pois conforme se analisou, os gestores públicos tendem a dar maior transparência a resultados positivos de sua gestão fiscal.

Destaca-se que se deve levar em consideração as características intrínsecas próprias do presente estudo as quais acabam por limitar outras possibilidades teóricas e instrumentais, assim como aos índices e proxies utilizados. Como sugestão para pesquisas futuras propõe-se identificar a influência dos custos de monitoramento no âmbito público sobre a Transparência Fiscal Ativa, ou mesmo a utilização de variáveis qualitativas na análise da Transparência.

\section{REFERÊNCIAS}

Alt, J. E.; Lassen D. D. \& Skilling, D. (2002). Fiscal Transparency, Gubernatorial Approval, and the Scale of Government: Evidence from the States. State Politics \& Policy Quarterly, 2(3) 230-250.

Alt, J. E., Lassen D. D., \& Rose, S. (2006). The causes of fiscal transparency: evidence from the American States. IMF Staff Papers, 53, Special Issue, 30-57.

Araújo, X. M. B., Kronbauer, C. A., Carvalho, J. R. M., \& Cirne, G. M. P. (2020). Quem está ficando para trás? Uma análise da transparência pública dos portais eletrônicos de municípios tocantinenses. Revista Contemporânea de Contabilidade, 17(44), 123-141.

Barros, L. M. (2014). Transparência fiscal eletrônica nos municípios do Estado do Paraná: avaliação do índice de transparência e as possíveis relações nesse processo. Dissertação de mestrado, Universidade Federal do Paraná, Paraná.

Brasil. Constituição da República Federativa do Brasil, de 05/10/1988. Recuperado em 30 de agosto de 2020, de http://www.planalto. gov.br/ccivil_03/Constituicao/Constituicao.htm.

Brasil. Lei complementar $n^{\circ} 101$, de 04/05/2000. Estabelece normas de finanças públicas voltadas à responsabilidade na gestão fiscal e dá outras providências. Recuperado em 30 de agosto de 2020, de http://www.planalto.gov.br/ccivil_03/leis/LCP/Lcp101.htm.

Brasil. Lei Complementar no 131, de 27/05/2009. Determina a disponibilização, em tempo real, de informações pormenorizadas sobre a execução orçamentária e financeira da União, dos Estados, do Distrito Federal e dos Municípios. Recuperado em 30 de agosto de 2020, de http://www.planalto.gov.br/CCivil_03/LEIS/LCP/Lcp131.htm.

Brasil. Lei ${ }^{\circ}$. 12.527, de 18 de novembro de 2011. Regula o acesso a informações previsto no inciso XXXIII do art. 5ㅜ, no inciso II do § 3º; do art. 37 e no $\S 2^{\circ}$; do art. 216 da Constituição Federal; altera a Lei no 8.112, de 11 de dezembro de 1990; revoga a Lei no11. 111, de 05 de maio de 2005, e dispositivos da Lei no 8.159, de 8 de janeiro de 1991; e dá outras providências. Recuperado em 30 de agosto de 2020, de http://www.planalto.gov.br/ccivil_03/_ato20112014/2011/lei/112527.htm.

Boubeta, A. S., Santias, F. R., \& Alegre, J. C. (2010). Budget Transparency in Local Government: Empirical Analysis on a Sample of 33 Galician Municipalities. XVII Encuentro De Economía Pública Murcia, 4, 1-30.

Brooks, C. (2002). Introductory econometrics for finance. Cambridge: Cambridge University Press.

Busuioc, M. E., \& Lodge, M. (2016) The Reputational Basis of Public Accountability. Journal of Policy, Administration and Institutions. 29(2), 247-263.

Chen, C., \& Neshkova, M. (2020). I The effect of fiscal transparency on corruption: A panel crosscountry analysis. Public Administration, 98(1), 226-243. 
Comin, D., Ramos, F. M., Zucchi, C., Favretto, J., \& Fachi, C. C. P. (2016). A Transparência Ativa nos Municípios de Santa Catarina: Avaliação do Índice de Atendimento à Lei de Acesso à Informação e suas Determinantes. Revista Catarinense da Ciência Contábil, 15(46), 24-34.

Cruz, C. F. (2015). Responsabilidade na Gestão Fiscal: um estudo em grandes municípios com base nos pilares da Lei de Responsabilidade Fiscal no período de 2010- 2013. 2015. 301 f. Tese (Doutorado em Controladoria e Contabilidade) - Universidade de São Paulo, Faculdade de Economia, Administração e Contabilidade, São Paulo.

De Renzio, P., \& Wehner, J. (2017). The impacts of fiscal openness. World Bank Research Observer, 32, 185-210.

ElBerry, N. A., \& Goeminne, S. (2020). Fiscal transparency, fiscal forecasting and budget credibility in developing countries. Journal of Forecasting. 1-18.

Firjan. (2017). Federação Da Indústria Do Estado Do Rio De Janeiro (FIRJAN). Índice Firjan de Gestão Fiscal. Ano Base 2016. Rio de Janeiro. Recuperado em 29 de janeiro de 2018, de: http://publicacoes.firjan.org.br/ifgf/2017/files/assets/common/downloads/publication.pdf

Gesuele, B., Metallo, C., \& Longobardi, S. (2018). The Determinants of E-Disclosure Attitude: Empirical Evidences from Italian and Spanish Municipalities. International Journal of Public Administration, (41)11, 921-934.

Hansen, S. W., Houlberg, K., \& Pedersen, L. H. (2014). Do municipal mergers improve fiscal outcomes? Scandinavian Political Studies, 37(2), 196-114.

Jensen, M., \& Meckling, W. (1976). Theory of The Firm: Managerial Behavior, Agency Costs and Ownership Structute. Journal of Financial Economics, 3(4), 305-360.

Kennedy, S., \& Robbins, J. (2001). The role of fiscal rules in determining fiscal performance. Working Paper, 16, Department of Finance.

Leite Filho, G. A.; Andrade, I. C. F.; \& Colares, A. F. V. (2014). Transparência Da Gestão Fiscal Pública: Um Estudo A Partir Dos Portais Eletrônicos dos maiores municípios do estado de Minas Gerais. Anais do Congresso Usp, São Paulo, SP, Brasil, 11.

Levine, D. M., Berenson, M. L., \& Stephan, David. (2000) Estatística: Teoria e Aplicações usando Microsoft Excel em Português. Rio de Janeiro.

Lewis, J. R. T. (2011). From Formal-passive to Informal-active Transparency:Freedom of Information, eGovernance and WikiLeaks. Global Conference on Transparency Research, 1, Rutgers University Newark, New Jersey.

Martins, P. L. (2011). Acesso à informação: Um direito fundamental e instrumental. Acervo, 24(1), 233-244.

Magalhães, E. A. (2017) Gestão Fiscal nos Municípios Brasileiros: Uma Análise das Diferenças Regionais. 125 f. Tese (Doutorado em Economia Aplicada) - Universidade Federal de viçosa, Minas Gerais.

Marques, S. B. S. da S. (2014). Transparência nos pequenos municípios do Rio Grande do Sul: um estudo sobre a divulgação de indicadores da LRF e da LAI. Dissertação de Mestrado em Ciências Contábeis da Universidade do Vale do Rio dos Sinos, São Leopoldo, RS, Brasil.

Meijer, A. (2009). Understanding modern transparency. International Review of Administrative Sciences, 75(2), 255-269. 
Mohamend, A. A., Gardner, W. L., \& Paolillo, J. G. P. (1999). A taxonomy of organizational impression management tactics. Advances in competitiveness research, 7(1), 108-130.

Mota, B. F., Diniz, J. A. \& Santos, L. C. (2017). A Estrutura Orçamentária como Determinante do Nível de Transparência Fiscal. Contabilidade, Gestão e Governança, 20(2), 293-313.

Nobre, C. J. F. (2017). A condição financeira governamental e sua influência na transparência da gestão pública municipal. 81 f. Dissertação (Mestrado em Ciências Contábeis) - Universidade Federal da Paraíba, João Pessoa/PB.

Pereira, J. R. T., Cordeiro, J. B. F. (2012). Rejeições de Prestação de Contas de Governos Municipais: O que está acontecendo? Contabilidade, Gestão e Governança, 15(1), 33-43.

Ribeiro, C. P. P., \& Zuccolotto, R. (2012). Fatores Determinantes da Transparência na Gestão Pública dos Municípios Brasileiros. ENAPG 2012. Salvador, BA. ANPAD.

Rosenfeld, P. (1997) Impression Management, Fairness and the Employment Interview. Journal of Business Ethics, 16(8), 801-808.

Sanchez, I. M. G., Aceituno, J. V. F., \& Domínguez, L. R. (2013). Determinants of corporate social disclousure in Spanish Local governments. Journal of Cleaner Production, 39, 60-72.

Santana Junior, J. J. B. (2008). Transparência fiscal eletrônica: uma análise dos níveis de transparência apresentados nos sites dos poderes e órgãos dos Estados e do Distrito Federal do Brasil. Dissertação (Mestrado em Ciências Contábeis) - Programa Multinstitucional e Inter-regional de Pósgraduação, Recife, PE.

Sarr, B. (2015). What are the drivers of fiscal performance gaps between Anglophone and Francophone Africa? A Blinder-Oaxaca decomposition. South African Journal of Economics, 84(1), 4062.

Stiglitz, J. E. (1999). On Liberty, the Right to Know, and Public Discourse: The Role. Globalizing Rights: The Oxford Amnesty Lectures 1999-2003. Recuperado em 16 de abril de 2017, de http://www.internationalbudget.org/wp-content/uploads/On-Liberty-the-Right-to-Know-andPublic-Discourse-The-Role-of-Transparency-in-Public-Life.pdf

Strumpf, K.S. (1998). A Predictive Index for the Flypaper Effect. Journal of Public Economics, 69, 389412.

Wehner, J., \& De Renzio, P. (2013). Citizens, legislators, and executive disclosure: The political determinants of fiscal transparency. World Development, 41, 96-108.

Wooldridge, J. M. (2006). Introdução à econometria: uma abordagem moderna. Pioneira Thomson Learning.

Wright, G. A. (2013). Análise dos fatores determinantes da transparência fiscal ativa nos municípios brasileiros. Dissertação de Mestrado, Programa Multiinstitucional e Inter-Regional de PósGraduação em Ciências Contábeis UnB/UFPB/UFRN, João Pessoa.

Wyckoff, P.G. (1988). A Bureaucratic Theory of Flypaper Effects. Journal of Urban Economics, 23, 115-129.

Zuccolotto, R., \& Teixeira, M. A. (2014). As causas da transparência fiscal: evidências nos estados brasileiros. Revista Contabilidade \& Finanças, 25(66), 242-254. 